\title{
Sobre la Medicina Apropiada, esa que todos llevamos dentro
}

R. Piñeiro Pérez

\author{
Servicio de Pediatría. Hospital General de Villalba. Collado Villalba. Madrid. España
}

Publicado en Internet:
24-marzo-2015
Roi Piñeiro Pérez:
roipineiro@telefonica.net

Dos y dos son cuatro, es algo indudable. Ni siquiera Denis Diderot se atrevería a cuestionar la certeza y exactitud de una ciencia pura y formal como las Matemáticas. Sin embargo, en Medicina no podemos afirmar nada con semejante rotundidad. Si acaso, podríamos sentarnos delante de nuestros pacientes y explicarles que, con un intervalo de confianza del $95 \%$, el resultado de la suma es un valor comprendido entre 3,9 y 4,1. Y, ante el asombro de padres y niños, añadiríamos: "aunque todo es posible".

Por si no fuera suficiente la imprecisión de nuestro arte curativo, nos rodean profesionales e instituciones que, cebados de experiencia, orgullo y una pizca de pavoneo, afirmarán que dos y dos son cinco. Porque la suma "siempre la hemos hecho así, y aquí nos ha ido bien". Parece evidente que este resultado no es apropiado, por lo que habría que revisar qué es lo que se está haciendo mal, encontrar la manera de aproximarnos al cuatro y respetar la evidencia científica actual. El escepticismo es el primer paso, y el más difícil, hacia la verdad. Solo el que dude del resultado de nuestras propias cuentas llegará a demostrar al resto del mundo que estábamos equivocados.
En esto consiste la Medicina Apropiada. En revisar lo que hacemos. En cuestionar nuestras prácticas. En evitar pruebas diagnósticas innecesarias y tratamientos ineficaces. En preguntarnos si realmente necesitamos pedir esa radiografía de tórax y prescribir ese antitusígeno. ¿Qué esperamos de ese antibiótico?, ¿cuántos meses de vida estamos regalando con esa estatina en la que hemos depositado toda nuestra fe?, ¿ por qué cuando todo falla usamos los corticoides?, ¿quién me convenció para usar ese inmunomodulador cuyo mecanismo de acción nadie cree?, ¿cuándo tendré un minuto para replantearme el pediatra que quiero ser? Quizá, ahora mismo, justo antes de saltar al siguiente párrafo, sea el momento apropiado.

No perdemos nada. En el peor de los casos estamos solo ante una nueva moda. Sin embargo, no cabe duda de que vivimos una Medicina de excesos, de sobrediagnósticos y sobretratamientos, de sistemas sanitarios enfermos cuya salud económica es cada vez más precaria. En el mejor de los casos buscamos racionalizar los recursos. No racionarlos, sino adecuar nuestros actos teniendo en cuenta la evidencia científica y las características de cada paciente. Debemos sentarnos y encontrar

Cómo citar este artículo: Piñeiro Pérez R. Sobre la Medicina Apropiada, esa que todos llevamos dentro. Rev Pediatr Aten Primaria. 2015;17:11-2. 
nuestro camino hacia lo que los ingleses Ilaman el right care. Pero ¿cómo ajustarnos a este cuidado apropiado?

Tenemos que conversar más con padres y niños e invitarles a cuestionar nuestros axiomas, a elegir con sabiduría ${ }^{1}$ (choosing wisely). Debemos aprender a hacer menos, a no hacer ${ }^{2,3}$ (do not do), entender que no es mejor médico quien más pruebas pide y más medicamentos prescribe. Es necesario asimilar que si no sabemos qué buscamos nunca podremos interpretar lo que encontramos, que muchas veces solicitar menos es más ${ }^{4}$ (less is more), y que nuestra obligación es centrarnos solo en lo esencial ${ }^{5}$ (essencial).

Un lactante menor de un año, tratado con procinéticos e inhibidores de la bomba de protones para controlar un reflujo fisiológico, microenemas y laxantes osmóticos para un estreñimiento funcional, corticoides inhalados por un episodio aislado de sibilancias, profilaxis antibiótica por dos infecciones de orina mal diagnosticadas y sales de hierro por una anemia que no es tal y nadie sospechó un rasgo talasémico. ¿Por qué a tantos pediatras no les Ilama la atención esto? ¿Por qué no dedicar un minuto a reevaluar lo que estamos haciendo? A buscar información, a encontrar evidencias. Nunca lo tuvimos tan fácil: a solo un clic de distancia.

El sofá está tan lleno de galenos acomodados que todos pensamos que jamás recuperará la flexibilidad que nos enamoró. Las guías de buena práctica clínica están tan cerca que incluso da miedo levantarse a por ellas. En cualquier caso nos da igual, porque "ya estudiamos en su día y ahora ya sabemos qué hay que hacer: lo de siempre". Sin embargo, ahí siguen los documentos de consenso, la evidencia científica, incitándonos constantemente a salir del sofá y ver el salón de otro color, a saltar al otro lado y salvar a nuestros colegas de la pereza ilustrada. A pensar, razonar, racionalizar, a buscar dentro de nosotros mismos y encontrar la Medicina Apropiada que todos llevamos dentro. Yo voy a empezar por pedir menos gammagrafías renales y a retirar algunas profilaxis con trimetoprim. ¿Alguien me sigue?

\section{BIBLIOGRAFÍA}

- Choosing Wisely. An initiative of the ABIM Foundation. En: Choosingwisely.org [en línea] [consultado el 24/03/2015]. Disponible en www.choosingwisely. org/updates-from-the-field/choosing-wisely-en-es panol/

- NICE 'do not do' recommendations. En: National Institute for Health Care and Excellence [en línea] [consultado el 24/03/2015]. Disponible en www.nice. org.uk/proxy/?sourceurl=http://www.nice.org.uk/ usingguidance/donotdorecommendations/index. jsp

- Recomendaciones de "no hacer" en Pediatría. En: Asociación Española de Pediatría [en línea] [consultado el 24/03/2015]. Disponible en www.aeped.es/ documentos/recomendaciones-no-hacer-en-pedia tria

- Less is more. En: The JAMA Network [en línea] [consultado el 24/03/2015]. Disponible en http://jama network.com/collection. aspx?categoryid $=6017$

- Essencial. Afegint valor a la pràctica clínica. En: Canal Salut, Generalitat de Catalunya [en línea] [consultado el 24/03/2015]. Disponible en http://essencialsa lut.gencat.cat/ca/que_es_essencial/ 